\title{
Molecular Determinants of the Bacterial Resistance to Fluoroquinolones: A Computational Study
}

\author{
Cecylia S. Lupala, Patricia Gomez-Gutierrez and Juan J. Perez
}

Department of Chemical Engineering, Universitat Politecnica de Catalunya, ETSEIB, Av. Diagonal, 647, 08028 Barcelona, Spain

\begin{abstract}
Quinolones constitute a large class of antibacterial agents whose action is mediated through the formation of a ternary complex with DNA and either, DNA Gyrase or topoisomerase IV, resulting in the inhibition of DNA replication. In order to get a deeper insight into the features of the complex formation, we carried out docking studies of fifteen diverse quinolones to the cleaved topoisomerase IV-DNA complex. Docking studies were performed using the crystal structures of the cleaved complex with levofloxacin and moxifloxacin (pdb entries $3 \mathrm{~K} 9 \mathrm{~F}$ and $2 \mathrm{XKK}$, respectively) using the GOLD software. Ligands dock in positions similar to those of the crystal structures. Analysis of the results reveals that bound quinolones appear intercalated between the two nucleotides that are involved in the DNA cleavage and exhibit hydrogen bonds with $\mathrm{Arg}^{117}$ and, the latter mediated though a water molecule. $\mathrm{Arg}^{117}$ has not been described to be involved in resistance, since it is putatively involved in the enzymatic reaction and its mutation would be lethal for the organism. Mutants of $\mathrm{Ser}^{79}$ exhibit resistance to quinolones which can be explained by the loss of an important anchoring point. Interestingly, quinolone resistance observed in $\mathrm{Asp}^{83}$ mutants cannot be explained directly on the basis of the loss of a direct interaction, but could be explained on the basis of its involvement at the entrance of the ligands to their binding pocket since the residue is located at the mouth of the pocket. The results of the present study suggest that the 4-keto and 3-carboxyl groups of the fluoroquinolones bind a $\mathrm{Mg}^{2+}$ before binding to the cleaved topoisomarase IV-DNA complex and use $\mathrm{Asp}^{83}$ for entry into the binding pocket. Accordingly, mutations that do not conserve the binding capacity for the quinolone- $\mathrm{Mg}^{2+}$ complex will prevent the binding of this class of ligands. The results we present here are also compared with the structure of PD0305970 a 2,4-dione active against the $\mathrm{Ser}^{79}$ and $\mathrm{Asp}^{83}$ mutants.
\end{abstract}

Keywords: Quinolones, topoisomerase IV, DNA gyrase, antibiotic resistance, antibiotics mode of action.

\section{INTRODUCTION}

Antibiotic resistance is a major public health concern of modern society. Infections caused by resistant pathogens have serious consequences, including an increased risk of death, hampering of infectious disease control and raising the threat of a return to the pre-antibiotic era [1]. Quinolones constitute a large class of synthetic antimicrobial agents with a $17 \%$ share of the world antibiotic market [2]. They are effective for the treatment of many types of infectious diseases caused by bacteria, being clinically used to treat infections of the urinary tract and respiratory system mainly, although they are also used for the treatment of sexually transmitted diseases, bone and joint infections or typhoid fever [3, 4]. Quinolones exhibit properties of the ideal antibiotic: high potency, a broad spectrum of activity, good bioavailability, oral and intravenous formulations, high serum levels, a large volume of distribution indicating concentration in tissues and a potentially low incidence of side-effects. However, after some years of quinolone use, resistance in Enterobacteriaceae has become common, wide spread and non-clonal [5] forcing the need to develop new analogs.

*Address correspondence to this author at the Department of Chemical Engineering, Universitat Politecnica de Catalunya, ETSEIB, Av. Diagonal, 647, 08028 Barcelona, Spain; Tel: +34934016679; Fax: +34934017150;

E-mail: juan.jesus.perez@upc.edu
From the chemical point of view, quinolone is a generic term, used loosely to refer to different chemical structures that have a 4-oxo-1, 4-dihydroquinoline skeleton shown in Fig. (1), most often with a carboxylic acid attached at position 3 [6, 7]. Nalidixic acid (see Fig. 1) was the first member of this family to be released in the early sixties, with a moderate antibacterial activity and narrow Gram-negative spectrum. The substitution of a piperazine ring at position R7 and the addition of a fluorine atom at position R6, resulted in an increase of potency and spectrum of activity to Grampositive bacteria, giving rise to a second generation of quinolones, about a decade later. A third generation came a few years later with the popular addition of a cyclopropyl group at position R1 together with substitution of methoxy or chlorine moieties at position R8. The cyclopropyl moiety enhances potency and has some effects on pharmacokinetics. Different structure-activity studies have provided evidence of the effect of different substitutions on the 4-quinolone scaffold. Thus, it is known that bulky substituents at position R2 lower the microbiological activity due to steric hindrance. Only sulfur, incorporated into a small ring as in the case of the thiazetoquinolones, has been able to replace hydrogen at the R2 position. Substituents at R5 position appear to have the capacity to alter overall steric configuration (planar structure) of the molecule, which is why changes here are thought to affect activity. Modestly sized additions, such as an amino, hydroxyl, or methyl groups can markedly increase in vitro activity against Grampositive bacteria as well as enhance potency. It is also known 
<smiles>[R]c1c([R])c([R8])c2c(c1[R])c(=O)c(C(=O)O)c([R])n2[R1]</smiles>

4-oxo-1,4dihydroquinoline skeleton<smiles>CCn1cc(C(=O)O)c(=O)c2ccc(C)nc21</smiles>

Naxilic acid<smiles>CC1COc2c(N3CCN(C)CC3)c(F)cc3c(=O)c(C(=O)O)cn1c23</smiles>

Levofloxacin<smiles>COc1c(C2CC3CCCNC3C2)c(F)cc2c(=O)c(C(=O)O)cn(C3CC3)c12</smiles><smiles>O=C(O)c1cn(C2CC2)c2cc(N3CCNCC3)c(F)cc2c1=O</smiles><smiles>Cc1c(N2CCC(CN)C2)c(F)cc2c1N1C(=O)C(N)C(=O)N1C1CC21</smiles>

Fig. (1). General scheme and numbering of the 4-oxo-1,4-dihydroquinoline scaffold and the chemical structures of different quinolone analogs: Nalidixic acid; levofloxacin; moxifloxacin; ciprofloxacin; PD0305970.

that a fluorine atom at position R6 controls bacterial potency or that the presence of a bulky ring at position R7 controls potency spectrum and pharmacokinetics. Finally, the heterocycle scaffold can also be modified. Thus, when position R8 is changed for nitrogen, the family of napthylridines produced exhibit also high antibiotic activity. Similarly, quinazolines, quinazolinediones [8-10] or isothioquinolones [11] have also proved to have high antibiotic activity.

The therapeutical targets of quinolones are two bacterial type II topoisomerases: DNA gyrase and topoisomerase IV [12]. Type II topoisomerases regulate the overwinding or underwinding of DNA by creating transient breaks on the two DNA strands (known as the cleaved complex) and reseal them, after passing another unbroken DNA double strand through it. Both are tetrameric proteins formed by two (duplicated) subunits. In the case of gyrase they are called GyrA and GyrB subunits, whereas in the case of topoisomerase IV they are called ParC and ParE subunits. Gyrase tends to be the primary target in Gram-negative bacteria, while the activity of topoisomerase IV is preferentially inhibited by most quinolones in Gram-positive organisms, but this may vary with the drug. Quinolones bind to the transient topoisomerases-DNA complex preventing religation of DNA ends. The subsequent release of DNA from protein constraints fragments chromosomes, causing cell death [13].

Regular uses of quinolones in the past more than forty years have raised resistant strains against them. Resistance arises from mutations that either alter drug uptake and efflux or affect binding interactions between the target enzyme and the quinolones, being this latter the main mechanism of bacterial resistance [14]. Mutations affecting the binding of quinolones more frequently affect a region of the protein called quinolone-resistant determining region located either in the N-terminal domains of ParC and GyrA or in the Cterminal domain of ParE. In ParC subunit of Streptococcus pneumonia topoisomerase IV, the most common mutations are S79A, S79W and D83Y, D83G, D83H, D83N, and D83A [15].

Knowledge of the structural features that control ligandreceptor interaction at the atomic level is crucial for designing new quinolones to be active to resistant strains. The recent release of the crystallographic structures of the cleaved topoisomerase IV-DNA-quinolone ternary complexes with levofloxacin shown in Fig. 1 (pdb entry 3K9F) [16]; moxifloxacin (see Fig. 1) (pdb entry 2XKK) [17], ciprofloxacin, shown in Fig. 1 (pdb entry 2XCT) [18] and PD0305970, shown in Fig. 1 (pdb entry 3LTN) [16] have contributed to a better understanding of quinolone mechanism of action. Superimposition of the crystallographic structures of the four cleaved DNAtopoisomerase IV-quinolone complexes (shown in Fig. 3), shows the ligands occupying the same binding pocket and oriented in the same pose, suggesting that the modification from a 3-carboxylic acid, 4-ketone to a 2,4-dione does not alter the binding mode of the ligand to the target protein. Bound quinolones are found intercalated between the two nucleotides involved in the DNA cut, and oriented in such a way that some moieties interact with specific residues of the ParC subunit, including $\mathrm{Arg}^{117}$ and $\mathrm{Ser}^{79}$. Specifically, the four molecules exhibit a hydrogen bond with $\mathrm{Arg}^{117}$ : in the case of the dione involving the carbonyl located in R2, whereas in the case of the fluoroquinolones the carboxylic group in R3. The three fluoroquinolones also exhibit a hydrogen bond interaction with the side chain of $\operatorname{Ser}^{79}$. In the case of ciprofloxacin is a direct interaction, whereas in the case of levofloxacin and moxifloxacin it is mediated through a water molecule. Furthermore, analysis of the moxifloxacin and ciprofloxacin structures reveals that the $\operatorname{Ser}^{79}$ side chain is involved in an interaction with a divalent ion $\left(\mathrm{Mg}^{2+}\right.$ in the former and $\mathrm{Mn}^{2+}$ in the latter) mediated through a water molecule. No divalent ion is found in the structure with levofloxacin [16]. On the opposite region of the ligand structure, the bulky moiety in $\mathrm{R} 7$ projects into a large solvent-accessible volume. This region in topoisomerase IV contains several polar interconnected residues, including 
$\mathrm{Asp}^{435}, \mathrm{Glu}^{474}, \mathrm{Glu}^{475}$ and $\mathrm{Arg}^{456}$ that create an environment adequate to host a polar/charged moiety. In fact, PD0305970 takes advantage of it with an amine group that is found interacting with $\mathrm{Glu}^{474}$ and the backbone carbonyl of $\mathrm{Arg}^{456}$. Finally, all the structures show one of the two catalytic $\mathrm{Mg}^{2+}$ coordinated by residues $\mathrm{Asp}^{508}$ and $\mathrm{Asp}^{506}$ [19].

In spite of the wealth of information provided by the crystallographic structures, there are uncertainties surrounding the exact details of the quinolone-DNA and quinolone-protein interaction in part associated with the degree of resolution of the different structures. In addition, it is very likely that different quinolones will have different specific interactions with their target, and these will also vary depending on the target (gyrase or topoisomerase IV). An intriguing question remaining regards the role played by $\mathrm{Mg}^{2+}$ in quinolone binding. Thus, in addition to its well established role for DNA cleavage [20,21], it is known that the divalent ion is necessary for quinolone action [21, 22]. In fact, two of the three crystallographic structures of the cleaved topoisomerase IV-DNA-quinolone ternary complex available show a divalent ion $\left(\mathrm{Mn}^{2+}\right.$ in the complex with ciprofloxacin) bound to the $\mathrm{C} 3 / \mathrm{C} 4$ keto acid moiety of the quinolone molecule with four water molecules saturating the rest of its octahedral coordination shell. Inspection of the structures suggests that the loss of activity of quinolones when $\mathrm{Ser}^{79}$ is mutated can be attributed to the corresponding loss of the interaction serine side chain-water-ion [17, 22]. However, it is not clear if this hypothesis can be extended to explain the observed resistance when $\mathrm{Asp}^{83}$ is mutated? Furthermore, why the ion bound to the quinolones is not directly bound to $\mathrm{Ser}^{79}$ and $\mathrm{Asp}^{83}$ side chains in contrast to the one found in the catalytic site? Why the crystallographic structure of the complex with levofloxacin does not exhibit any ion bound to the quinolone?

Thus, a deeper understanding of the structure-activity relationships exhibited by this family of compounds, as well as characterization of the structural reasons for certain mutations to make strains resistant or the mechanism of quinolone binding at the atomic level, will be useful for designing new analogs. Computational techniques represent an adequate alternative and companion to experimental methodologies in providing insightful atomic level structural information and interactions knowledge. Accordingly, we have analyzed the structural features of 15 complexes of different quinolone analogs bound to the cleaved DNAtopoisomerase IV and the results of this comparative analysis are reported in the present work. These molecules have been selected to cover the maximum structural diversity of the quinolones so far described.

\section{METHODS}

The ternary cleaved of DNA-topoisomerase IV structures from Streptococcus pneumoniae and Acinetobacter baumannii with levofloxacin and moxifloxacin bound (pdb entries $3 \mathrm{~K} 9 \mathrm{~F}$ and $2 \mathrm{XKK}$ ) respectively, (with their respective ligands removed) were used as templates for the modeling studies described in the present work. The templates were pre-processed using the Molecular Operating Environment (MOE) [23] software, including assignment of side change ionization states, addition of missing residues and hydrogens. Crystallographic waters were kept to perform the present study. In order to characterize the features of the binding pocket, the MOE software was used to compute interaction maps using probes of different nature. Maps produced by a hydrophobic, proton acceptor and proton donor probes were used to supervise the results of subsequent docking studies.

Docking of a group of diverse fifteen fluoroquinolones (including levofloxacin, ciprofloxacin and moxifloxacin) was carried out. The group of quinolones includes clinafloxacin, garenoxacin, gatifloxacin, gemifloxacin, ofloxacin, prulifloxacin, sitafloxacin, trovafloxacin, temafloxacin, grepafloxacin, sparfloxacin, and tosufloxacin, whose structures are shown in Fig. (2). Fluoroquinolones were docked into the binding pocket of the templates using the Genetic Optimization for Ligand Docking software (GOLD) version 5.1 with the goldscore scoring function [24, 25].

In addition, in order to understand the effect of resistant mutations on quinolone binding, mutants S79A and D83Y as well as the double mutation $(\mathrm{S} 79 \mathrm{~A}+\mathrm{D} 83 \mathrm{Y})$ were generated using the topoisomerase IV-moxifloxacin complex (pdb entry $3 \mathrm{~K} 9 \mathrm{~F}$ ). These proteins were used to construct fifteen different complexes of each, using the ligands of Fig. (2) together with moxifloxacin, ciprofloxacin and levofloxacin. Docking studies were carried out as described above.

\section{RESULTS AND DISCUSSION}

We carried out docking of the twelve analogs listed in Fig. (2) together with moxifloxacin, ciprofloxacin and levofloxacin, using the structures of pdb code $2 \mathrm{XKK}$ and $3 \mathrm{~K} 9 \mathrm{~F}$ as target macromolecules. The main difference between the two structures is the lack of a bound $\mathrm{Mg}^{2+}$ in the fluoroquinolone site in the latter. One of the outcomes of this study is that there are no differences when the structures are docked to either protein, suggesting that the quinolonebound $\mathrm{Mg}^{2+}$ ion is not crucial for an adequate positioning of the ligand in the binding pocket. As found in the crystallographic structures, the quinolone structure exhibits a stacking interaction with the nucleotides involved in the DNA cut. In addition, the 3-carboxyl group establishes a direct hydrogen bond with $\mathrm{Arg}^{117}$ and a water mediated hydrogen bond with the residue $\mathrm{Ser}^{79}$.

\section{Structure-Activity Relationships}

A comparative analysis of the docked structures permits to identify common stereoelectronic features in each of the different substitutions on the quinolone scaffold, once the ligands are superimposed in their actual positions inside the binding pocket. Thus, when a hydrophobic probe is used to scan the binding pocket without any ligand, three areas are found for the preferential location of a hydrophobic moiety. First, the region where the fused rings sit intercalated between the nucleotides. Second, an area in the neighborhood of position R1, which justifies the use of cyclopropane as substituent in nine of the analogs studied. In addition to cyclopropane, other hydrophobic moieties, like difluorobenzene found in trovafloxacin, temafloxacin or tosufloxacin or the thiazetoquinolone skeleton, as in prulifloxacin, fit well within the hydrophobic area as can be seen in Fig. (4). The third area for favorable hydrophobic 
<smiles>COc1c(N2C[C@@H]3CCCN[C@@H]3C2)c(F)cc2c(=O)c(C(=O)O)cn(C3CC3)c12</smiles><smiles></smiles><smiles>C[C@H]1CC2C=CC(c3ccc4c(c3OC(F)F)C(O)C(C(=O)O)CN4C3CC3)=CC2CN1</smiles><smiles>COc1c(N2CCNCC2)c(F)cc2c(=O)c(C(=O)O)cn(C3CC3)c12</smiles><smiles>CO/N=C1\CN(c2ccc3c(=O)c(C(O)O)cn(C4CC4)c3n2)CC1CN</smiles>

Garenoxacin Gatifloxacin Gemifloxacin<smiles></smiles><smiles>CC1Sc2c(C(=O)O)c(=O)c3cc(F)c(N4CCNCC4)cc3n21</smiles><smiles>CC(F)(F)n1cc(C(=O)O)c(=O)c2cc(F)c(N3C[C@@H](N)C4(CC4)C3)c(Cl)c21</smiles>

Ofloxacin

Ulifloxacin<smiles>CC12CN(c3nc4c(cc3F)c(=O)c(C(=O)O)cn4-c3ccc(F)cc3F)CC1C2N</smiles><smiles>C[C@H]1CN(c2cc3c(cc2F)c(=O)c(C(=O)O)cn3-c2ccc(F)cc2F)CCN1</smiles><smiles>Cc1c(F)c(N2CCNC(C)C2)cc2c1c(=O)c(C(=O)O)cn2C1CC1</smiles>
Trovafloxacin Temafloxacin<smiles>C[C@H]1CN(c2c(F)c(N)c3c(=O)c(C(=O)O)cn(C4CC4)c3c2F)C[C@@H](C)N1</smiles><smiles>NC1CCN(c2nc3c(cc2F)c(=O)c(C(=O)O)cn3-c2ccc(F)cc2F)C1</smiles>

Fig. (2). Chemical structures of the fifteen quinolones selected for the present study.

interactions which have been largely exploited lies in the neighborhood of the R7 substituent, distant from the fused rings. In both crystal and docked structures, bulky substituents in R7 occupy a large pocket created between the DNA and the ParE subunit. In contrast, in PD0305970 the substitution ion R7 exploits an area with a few polar conserved residues. This indicates that bulkier substitutions are possible and can be harnessed to promote ligand-enzyme interactions at this position as seen in some of the new fluoroquinolones [26]. SAR studies have proven that a bulky substituent at R7 tends to lead to reduced side effects, improved potency and in vivo efficacy against Gram positive species [10, 27-30].

Few substitutions have proven to be successful in position R5. Possible substituents in this position cannot be bulky because it would interfere the stacking interaction between the drug and the nucleotides. Thus, a methyl group like in grepafloxacin or an amine group like in sparfloxacin have been credited with an increase in drug potency against Gram positive bacteria [31].
In regard to the R6 substituents, a fluorine atom in this position has been demonstrated to be important for quinolone binding. Since quinolone binding can be largely explained on the basis of a stacking interaction of the quinolone molecule with the flanking nucleotides, enhancement of this interaction will improve the affinity of the ligand. Indeed, an important component of this binding is due to the quadrupole-quadrupole interactions, so an electronegative substituent with capacity to modulate the quadrupole moment of the ligand, will increase these interactions. On the other hand, as discussed for position R5, substituents cannot be bulky due to steric contacts with neighboring nucleotides. Accordingly, fluorine fulfills all the requirements and the reason to have been difficult to substitute.

Among many structural modifications investigated in R8 position, few substituents such as fluoro, chloro, methyl, and methoxy groups render an increase in antibacterial activity, especially against Gram-positive bacteria and enhanced 


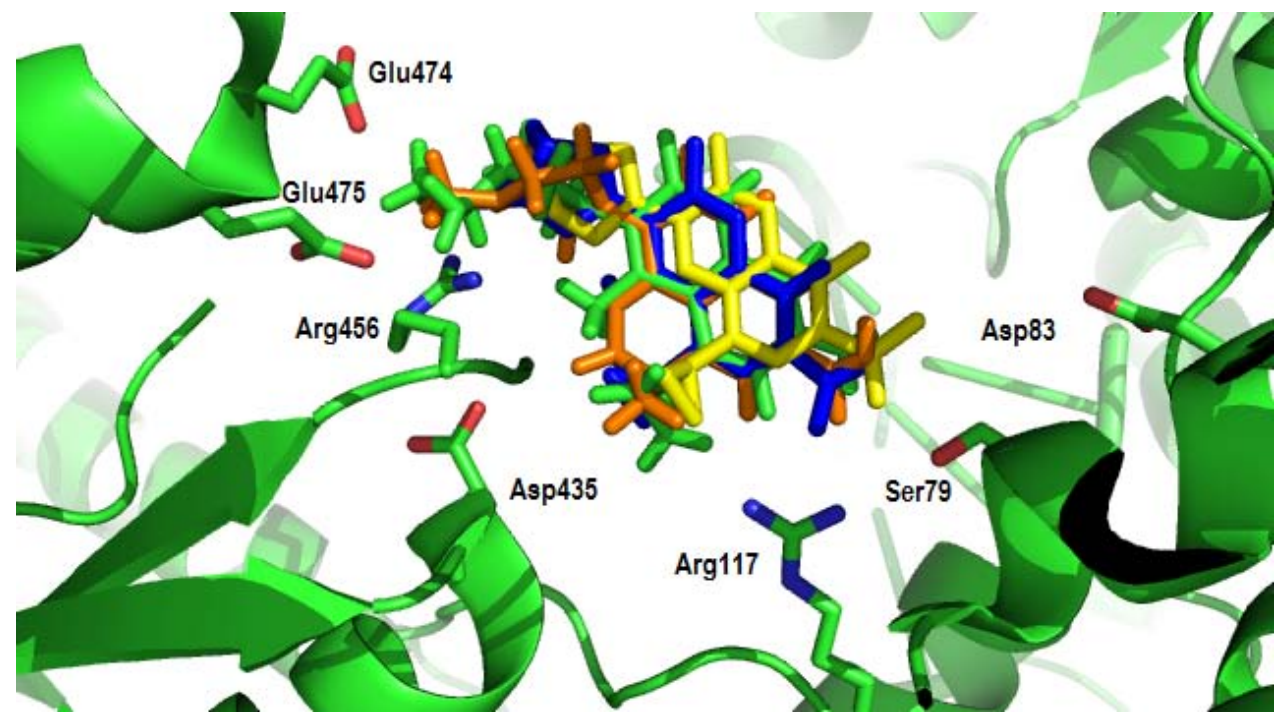

Fig. (3). Superimposition of the crystal structures 3K9F, $2 \mathrm{XKK}$ and $3 \mathrm{LTN}$ showing the overlapping between the different quinolones: levofloxacin (orange), moxifloxacin (navy blue), ciprofloxacin (yellow) and PD0305970 (green), respectively. For interpretation of references to color in this figure legend, the reader is referred to the web version of this paper.

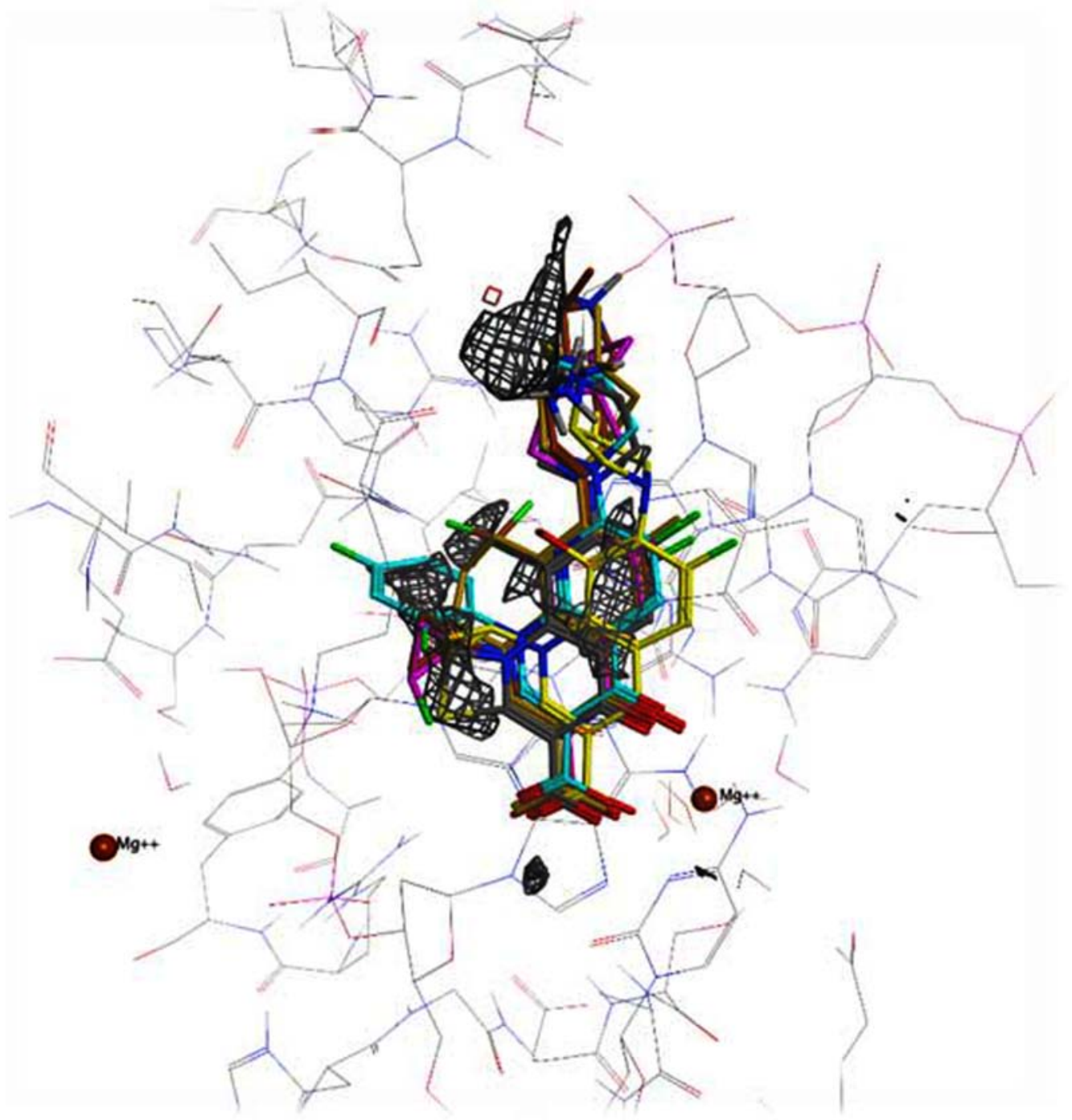

Fig. (4). Hydrophobic map of the quinolones (moxifloxacin in green, prulifloxacin in pink, levofloxacin in yellow and Tosufloxacin in dark orange) showing hydrophobic area (in silver) around the R1 and R5 of the quinolones (and nearby receptor atoms). For interpretation of references to color in this figure legend, the reader is referred to the web version of this paper. 
potency against anaerobes [32]. Furthermore, the influence of 5-amino group in sparfloxacin has been reported to depend on the substitution pattern of R8 and R1. Thus, while we could not find direct structural interaction between the substituents at these positions and the receptor, their selfassociation may well be their contribution to the ligand activity. In regard to position R2, the models show that although there is enough room to host different chemical moieties, there are no side chains neither of the protein or the DNA, available to produce favorable interactions with the ligand in order to improve the affinity of these analogs. The only quinolones described with a substitution in this position are the thiazetoquinolones. The favorable role of this moiety can be explained on the basis of the bulkiness of the sulphur atom, capable to establish a hydrophobic interaction with the two nucleotides flanking the quinolone binding site.

\section{Quinolone Binding}

In order to assess the importance of different interactions acting on quinolone binding, we performed docking studies of the fifteen analogs onto the DNA with the protein removed and vice versa, onto the protein with the DNA removed, using the same structures as templates. When docking the quinolones on the DNA structure, it can be seen that they accommodate intercalated between the two nucleotides involved in the DNA cut, but adopt systematically a pose in different orientation in regard to the crystallographic structure. This suggests that the stacking interactions are strong enough to bind the ligands, but unable to orient them properly, needing additional anchoring points for a correct docking orientation that is provided by the protein. On the other hand, when the docking is performed on the protein alone, the molecule accommodates on top of residues $\mathrm{Ser}^{79}$ and $\mathrm{Asp}^{83}$ as had been observed previously [33]. Taking these observations together with the known experimental results available, it is reasonable to consider that the molecule does not bind to any of the two macromolecules prior to complex formation [34, 35].

Although $\mathrm{Mg}^{2+}$ is necessary for the catalytic action of topoisomerase, its role in quinolone binding is enigmatic. It is surprising that one of the structures does not exhibit the ion coordinated with levofloxacin. Since the docking study of the different quinolones described above provides the same results with or without the presence of the magnesium ion, it could be thought that the ion is not important for the pose taken by the ligand when bound. This result raises the question whether the ion is already in the protein prior to ligand binding or it is borne by the quinolones. In fact, quinolones are important chelating agents with high affinity for different ions, including $\mathrm{Mg}^{2+}[36,37]$. Moreover, the fact that EDTA reverses the action of quinolones can be explained by its sequestering capacity that would limit the number of quinolone- $\mathrm{Mg}^{2+}$ molecules available in solution, reversing the binding [38]. In order to shed some light into this question we proceeded to identify favorable sites for a magnesium ion to sit in the binding pocket of the transient toposiomerase-DNA complex by computing the interaction map inside the binding pocket using the structures $3 \mathrm{~K} 9 \mathrm{~F}$ and $2 \mathrm{XKK}$ with the quinolone removed, by means a magnesium probe. Inspection of the interaction maps permits to identify the site of the catalytic magnesium but not that of the quinolone. However, when the maps are computed with the quinolone bound a favorable site close to the $\mathrm{C} 3 / \mathrm{C} 4$ keto acid moiety is identified. Moreover, for the $\mathrm{Mg}^{2+}$ to bind to the protein before ligand binds, it is not clear why it does not exhibit direct interactions with side chains of the receptor and only water mediated in contrast what is found in the catalytic site, where the ion binds directly to $\mathrm{Asp}^{508}$ and $\mathrm{Asp}^{506}$. Furthermore, this hypothesis provides an explanation to antibiotic resistance produced by mutations on $\mathrm{Asp}^{83}$ as explained below.

\section{Effect of Mutations on Ligand Binding}

In regard to the S79A mutation, docking structures onto the mutant protein reveal that the non-polar side chain of alanine prevents the interaction with the ligands and/or to the magnesium ion, with the subsequent loss of affinity. This is not observed in the 2,4-dione ligands, since $\mathrm{Ser}^{79}$ is not involved in a direct interaction with the ligand and the 2,4diones do not exhibit chelating properties [17, 22].

In the case of the D83Y mutant the effect of the mutation cannot be explained on the basis of a loss of affinity of the ligand, since the tyrosine side chain could hold a hydrogen bond with the quinolone. An alternative explanation can be argued by inspection of the protein surface. When the solvent accessible surface area of the protein is plotted, As ${ }^{83}$ is clearly identified at the mouth of the binding pocket like gatekeeper (see Fig. 5). Thus, it can be hypothesized that this residue is involved in the initial recognition step of the ligand. Accordingly, for the recognition step to be successful, quinolones should bear a charge complementary to aspartate, that could be provided by the $\mathrm{Mg}^{2+}$ bound to the quinolones providing a net positive charge. In the case of the mutant D83Y, although the side chain is bulkier it does not impede the binding of the 2,4-dione analogs. Thus, it could be thought that since the tyrosine side chain at physiological $\mathrm{pH}$ does not exhibit a negative charged side chain, there will not be a favorable interaction with $\mathrm{Mg}^{2+}$, impeding the initial binding step.

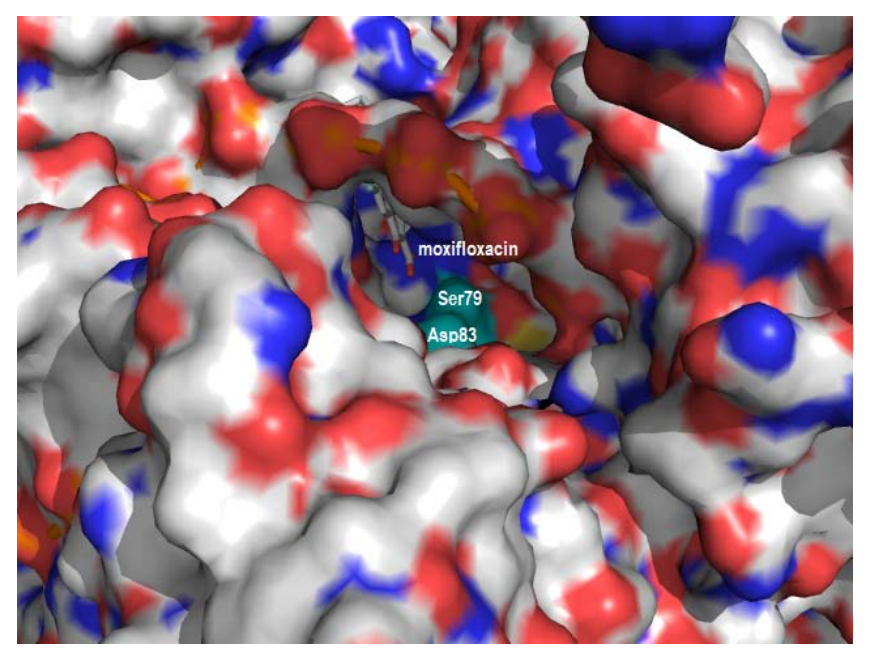

Fig. (5). Mouth of the putative entry point of quinolones to the cleaved complex topoisomarase IV-DNA shown in light blue the location of $\mathrm{Ser}^{79}$ and $\mathrm{Asp}^{83}$. For interpretation of references to color in this figure legend, the reader is referred to the web version of this paper. 


\section{CONCLUSIONS}

In this work we performed molecular modeling studies of the binding features of quinoloes using the available crystal structures of the topoisomerase IV-DNA cleaved complex with levofloxacin and moxifloxacin (pdb entries 3K9F and 2XKK, respectively) to account for the known structureactivity features of the quinolones and explain subsequently the resistance arose from amino acid alteration in the target enzymes, addressing simultaneously the role of $\mathrm{Mg}^{2+}$ in the process of quinolone binding. Specifically, we performed docking studies of a series of fifteen quinolones using both crystallographic structures alternatively. Analysis of the docked structures reveals that the binding of the different quinolones does not differ much from the poses of levofloxacin and moxifloxacin found in the crystal structures. Moreover, bound orientation of the ligands is not altered by the presence or not of a quinolone $\mathrm{Mg}^{2+}$, suggesting that the magnesium ion may already be bound to the quinolone before binding to the enzyme. This hypothesis provides an explanation for the resistance exhibited by different $\mathrm{Asp}^{83}$ mutants. Since the residue is located at the entrance of the binding pocket, it could be considered this residue to be putatively involved in the early recognition step of quinolones being able to bind to the quinolone- $\mathrm{Mg}^{2+}$ complex.

The importance of $\operatorname{Arg}^{117}$ and $\operatorname{Ser}^{79}$ for quinolone binding is reinforced by the computational work of the present report. Interestingly, the former is putatively involved in the mechanism of the enzymatic reaction and its mutation would be lethal, whereas the latter has been found mutated providing quinolone resistance. Comparison with the structure of PD0305970, a 2,4-dione analog was also performed. This compound is active against mutants at positions $\mathrm{Ser}^{79}$ and $\mathrm{Asp}^{83}$. In the case of the former it can be explained because its interaction with the ligand is not as important as in quinolones. In the case of the latter, it suggests that this ligand does not require this amino acid for entry to the binding pocket, possibly due to the lack of chelating capacity of the ligand.

The key to understand quinolone action lies on our knowledge of the binding process. Thus, the future of quinolone research is entwined with the detailed understanding of the formation of quinolone-protein-DNA complex. The present study also raises a question on the future of quinolones as therapeutic agents. Knowledge of the structure of the complex and a plausible mechanism of binding provides us with important information to design new quinolones with improved drug-target interactions.

\section{CONFLICT OF INTEREST}

The authors confirm that this article content has no conflicts of interest.

\section{ACKNOWLEDGEMENTS}

Prof. Luis del Valle is gratefully acknowledged for insightful discussions.

\section{REFERENCES}

[1] Rice, L.B. Federal funding for the study of antimicrobial resistance in nosocomial pathogens: no ESKAPE. J. Infect. Dis., 2008, 197, 1079-1081.

[2] Hamad, B. The antibiotics market. Nat. Rev. Drug Discov., 2010, 9 , 675-676.

[3] Wolfson, J.S.; Hooper, D.C. Fluoroquinolone antimicrobial agents Clin. Microbiol. Rev.,1989, 2, 378-424.

[4] Bolon, M.K. The newer fluoroquinolones. Infect. Dis. Clin. North Am., 2009, 23, 1027-1051.

[5] Rodriguez-Martinez, J.M.; Cano, M.E.; Velasco, C.; MartinezMartinez, L.; Pascual, A. Plasmid-mediated quinolone resistance: an update. J. Infect. Chemother., 2011, 17, 149-182.

[6] Andersson, M.I.; MacGowan, A.P. Development of the quinolones. J. Antimicrob. Chemother., 2003, 51, 1-11.

[7] Mitscher, L.A. Bacterial topoisomerase inhibitors: quinolone and pyridone antibacterial agents. Chem. Rev., 2005, 105, 559-592.

[8] Malik, M.; Marks, K.R.; Mustaev, A.; Zhao, X.; Chavda, K.; Kerns, R.J.; Drlica, K. Fluoroquinolone and quinazolinedione activities against wild-type and gyrase mutant strains of Mycobacterium smegmatis. Antimicrob. Agents Chemother., 2011, $55,2335-2343$

[9] Pan, X.S.; Gould, K.A.; Fisher, L.M. Probing the differential interactions of quinazolinedione PD 0305970 and quinolones with gyrase and topoisomerase IV. Antimicrob. Agents Chemother., 2009, 53, 3822-3831.

[10] Tran, T.P.; Ellsworth, E.L.; Sanchez, J.P.; Watson, B.M.; Stier, M.A.; Showalter, H.D.; Domagala, J.M.; Shapiro, M.A.; Joannides, E.T.; Gracheck, S.J.; Nguyen, D.Q.; Bird, P.; Yip, J.; Sharadendu, A.; Ha, C.; Ramezani, S.; Wu, X.J.; Singh, R. Structure-activity relationships of 3-aminoquinazolinediones, a new class of bacterial type-2 topoisomerase (DNA gyrase and topo IV) inhibitors. Bioorg. Med. Chem. Lett., 2007, 17, 1312-1320.

[11] Kim, H.Y.; Wiles, J.A.; Wang, Q.; Pais, G.C.; Lucien, E.; Hashimoto, A.; Nelson, D.M.; Thanassi, J.A.; Podos, S.D.; Deshpande, M.; Pucci, M.J.; Bradbury, B.J. Exploration of the activity of 7-pyrrolidino-8-methoxyisothiazoloquinolones against methicillin-resistant Staphylococcus aureus (MRSA). J. Med. Chem., 2011, 54, 3268-3282.

[12] Deweese, J.E.; Osheroff, N. The DNA cleavage reaction of topoisomerase II: wolf in sheep's clothing. Nucleic Acids Res., 2009, 37, 738-748.

[13] Collin, F.; Karkare, S.; Maxwell, A. Exploiting bacterial DNA gyrase as a drug target: current state and perspectives. Appl. Microbiol. Biotechnol., 2011, 92, 479-497.

[14] Pantosti A.; Sanchini A.; Monaco M. Mechanisms of antibiotic resistance in Staphylococcus aureus. Future Microbiol., 2007, 2, 323-334.

[15] Patel, S.N.; Melano, R.; McGeer, A.; Green, K.; Low, D.E. Characterization of the quinolone resistant determining regions in clinical isolates of pneumococci collected in Canada. Ann. Clin. Microbiol. Antimicrob., 2010, 9, 3-6.

[16] Laponogov, I.; Pan, X.S.; Veselkov, D.A.; McAuley, K.E.; Fisher, L.M.; Sanderson, M.R. Structural basis of gate-DNA breakage and resealing by type II topoisomerases. PLoS One, 2010, 5, e11338.

[17] Wohlkonig, A.; Chan, P.F.; Fosberry, A.P.; Homes, P.; Huang, J.; Kranz, M.; Leydon, V.R.; Miles, T.J.; Pearson, N.D.; Shillings, A.J.; Gwynn, M.N.; Bax, B.D. Structural basis of quinolone inhibition of type IIA topoisomerases and target-mediated resistance. Nat. Struct. Mol. Biol., 2010, 17, 1152-1153.

[18] Bax, B.D.; Chan, P.F.; Eggleston, D.S.; Fosberry, A.; Gentry, D.R.; Gorrec, F.; Giordano, I.; Hann, M.M.; Hennessy, A.; Hibbs, M.; Huang, J.; Jones, E.; Jones, J.; Brown, K.K.; Lewis, C.J.; May, E.W.;Saunders, M.R.; Singh, O.; Spitzfaden, C.E.; Shen, C.; Shillings, A.; Theobald, A.J.; Wohlkonig, A.; Pearson, N.D.; Gwynn, M.N. Type IIA topoisomerase inhibition by anew class of antibacterial agents. Nature, 2010, 466, 935-940.

[19] Schmidt, B.H.; Burgin, A.B.; Deweese, J.E.; Osheroff, N.; Berger, J.M. A novel and unified two metal mechanism for DNA cleavage by type II and IA topoisomerases. Nature, 2010, 465, 641-645. 
[20] Pitts, S.L.; Liou, G.F.; Mitchenall, L.A.; Burgin, A.B.; Maxwell, A.; Neuman, K.C.; Osheroff, N. Use of divalent metal ions in the DNA cleavage reaction of topoisomerase IV. Nucleic Acids Res., 2011, 39, 1-10.

[21] Sissi, C.; Andreolli, M.; Cecchetti, V.; Fravolini, A.; Gatto, B.; Palumbo, M. Mg2+-Mediated binding of 6-substituted quinolones to DNA: relevance to biological activity. Bioorg. Med. Chem., 1998, $6,1555-1561$

[22] Aldred, K.J.; McPherson, S.A.; Wang, P.; Kerns, R.J.; Graves, D.E.; Turnbough, Jr. C.L.; Osheroff, N. Drug interactions with Bacillus anthracis topoisomerase IV: biochemical basis for quinolone action and resistance. Biochemistry, 2012, 51, 370-381.

[23] Vilar, S.; Cozza, G.; Moro, S. Medicinal chemistry and the molecular operating environment (MOE): application of QSAR and molecular docking to drug discovery. Curr. Top. Med. Chem., 2008, $8,1555-1572$.

[24] Sousa, S.F.; Fernandes, P.A.; Ramos, M.J. Protein-ligand docking: current status and future challenges. Proteins, 2006, 65, 15-26.

[25] Verdonk, M.L.; Cole, J.C.; Hartshorn, M.J.; Murray, C.W.; Taylor, R.D. Improved protein-ligand docking using GOLD. Proteins, 2003, 52, 609-623.

[26] Morrow, B.J.; He, W.; Amsler, K.M.; Foleno, B.D.; Macielag, M.J.; Lynch, A.S.; Bush, K. In vitro antibacterial activities of JNJQ2, a new broad-spectrum fluoroquinolone. Antimicrob. Agents Chemother., 2010, 54, 1955-1964.

[27] Domagala, J.M. Structure-activity and structure-side-effect relationships for the quinolone antibacterials. J. Antimicrob. Chemother., 1994, 33, 685-706.

[28] Hooper, D.C. Mechanisms of action and resistance of older and newer fluoroquinolones. Clin. Infect. Dis., 2000, 31, S24-S28.

[29] Llorente, B.; Leclerc, F.; Cedergren, R. Using SAR and QSAR analysis to model the activity and structure of the quinolone-DNA complex. Bioorg. Med. Chem., 1996, 4, 61-71.

[30] Lubbers, T.; Angehrn, P.; Gmunder, H.; Herzig, S.; Kulhanek, J. Design, synthesis, and structure-activity relationship studies of ATP analogues as DNA gyrase inhibitors. Bioorg. Med. Chem. Lett., 2000, 10, 821-826.
[31] Pan, X.S.; Fisher, L.M. Targeting of DNA gyrase in Streptococcus pneumoniae by sparfloxacin: selective targeting of gyrase or topoisomerase IV by quinolones. Antimicrob. Agents Chemother., 1997, 41, 471-474.

[32] Yoshida, T.; Yamamoto, Y.; Orita, H.; Kakiuchi, M.; Takahashi, Y.; Itakura, M.;Kado, N.;Mitani, K.; Yasuda, S.; Kato, H.; Itoh, Y. Studies on quinolone antibacterials. IV. Structure-activity relationships of antibacterial activity and side effects for 5- or 8substituted and 5,8-disubstituted-7-(3-amino-1-pyrrolidinyl)-1cyclopropyl-1, 4-dihydro-4-oxoquinoline-3-carboxylic acids. Chem. Pharm. Bull. (Tokyo), 1996, 44, 1074-1085.

[33] Madurga, S.; Sanchez-Cespedes, J.; Belda, I.; Vila, J.; Giralt, E. Mechanism of binding of fluoroquinolones to the quinolone resistance-determining region of DNA gyrase: towards an understanding of the molecular basis of quinolone resistance. Chembiochem, 2008, 9, 2081-2086.

[34] Siegmund, K.; Maheshwary, S.; Narayanan, S.; Connors, W.; Riedrich, M.; Printz, M., et al. Molecular details of quinoloneDNA interactions: solution structure of an unusually stable DNA duplex with covalently linked nalidixic acid residues and noncovalent complexes derived from it. Nucleic Acids Res., 2005, 33 , 4838-4848.

[35] Shen, L.L.; Mitscher, L.A.; Sharma, P.N.; O'Donnell, T.J.; Chu, D.W.; Cooper, C.S.; Rosen, T.; Pernet, A.G. Mechanism of inhibition of DNA gyrase by quinolone antibacterials: cooperative drug--DNA binding model. Biochemistry, 1989, 28, 3886-3894.

[36] Lopez-Gresa, M.P.; Ortiz, R.; Perello, L.; Latorre, J.; LiuGonzalez, M.; Garcia-Granda, S.;Perez-Priede, M.;Canton, E. Interactions of metal ions with two quinolone antimicrobial agents (cinoxacin and ciprofloxacin). Spectroscopic and X-ray structural characterization. Antibacterial studies. J. Inorg. Biochem., 2002, 92, 65-74.

[37] Turel, I.; Sonc, A.; Zupancic, M.; Sepcic, K.; Turk, T. Biological activity of some magnesium(II) complexes of quinolones. Met. Based Drugs, 2000, 7, 101-104.

[38] Drlica, K.; Malik, M.; Kerns, R.J.; Zhao, X. Quinolone-mediated bacterial death. Antimicrob Agents Chemother., 2008, 52, 385-392. 